\title{
Một số yếu tố liên quan đến phục hình răng đã mất của người cao tuổi quận Cầu Giấy, Hà Nội
}

\author{
Đào Thị Dung ${ }^{1, *}$, Trần Ngọc Sơn ${ }^{2}$ \\ ${ }^{1}$ Khoa Y duợc, ĐHQGHN, nhà Y1, 144 Xuân Thủy, Cầu Giấy, Hà Nội, Việt Nam \\ ${ }^{2}$ Bệnh viện E, Số 89 Trần Cung, Phuờng Nghĩa Tân, Quận Cầu Giấy, Hà Nội, Việt Nam \\ Nhận ngày 26 tháng 2 năm 2016 \\ Chỉnh sửa ngày 08 tháng 3 năm 2017; Chấp nhận đăng ngày 14 tháng 6 năm 2017
}

Tóm tắt: Sức khỏe răng miệng người già ngày càng được chú ý đặc biệt là tình trạng mất răng và phục hình răng đã mất. Việc phục hình răng mất cho người cao tuổi là một việc cực kỳ quan trọng, nó giúp cải thiện trực tiếp đến chất lượng sống của họ. Mục tiêu: Nhận xét đặc điểm một số yếu tố liên quan đến vấn đề phục hình răng đã mất của người cao tuổi ở quận Cầu Giấy, Hà Nội. Phương pháp nghiên cứu mô tả cắt ngang, khám răng miệng cho 160 người cao tuổi, trong đó 141 người mất răng và chỉ có 76 người đã mang phục hình. Kết quả: Trình độ học vấn càng cao thì tỷ lệ có phục hình răng mất càng cao. Những nghề lao động chân tay có thu nhập thấp tỷ lệ phục hình các răng đã mất thấp hơn những nghề lao động trí óc. Những nghề yêu cầu giao tiếp nhiều có tỷ lệ phục hình răng mất cao. Nơi làm phục hình: chủ yếu là phòng khám chuyên khoa tư nhân, tiếp theo là bệnh viện. Thời gian sử dụng răng giả càng lâu thì chât lượng phục hình, cảm nhận của bệnh nhân về thẩm mỹ và khả năng ăn nhai đều giảm.

Từ khóa: Yếu tố liên quan đến phục hình răng mất.

\section{1. Đặt vấn đề}

Trong chương trình chăm sóc sức khỏe ở người cao tuổi, vấn đề sức khỏe răng miệng ngày càng được chú ý đặc biệt là tình trạng mất răng và phục hình răng đã mất. Việc mất một hoặc nhiều răng nếu không được phục hình đúng mức không chỉ có nghĩa là mất các chức năng của răng này mà còn ảnh hưởng tới chức năng của các răng còn lại của bộ răng và toàn bộ hệ thống nhai [1].

Vì vậy, việc phục hình răng mất cho người cao tuổi là một việc cực kỳ quan trọng, nó giúp cải thiện trực tiếp đến chất lượng sống của họ. Để đánh giá tình trạng phục hình các răng đã

\footnotetext{
*Tác giả liên hệ. ĐT.: 84-913236454.

Email: dungvncb@gmail.com

https://doi.org/10.25073/2588-1132/vnumps.4060
}

mất cần có những điều tra đánh giá về về một số yếu tố liên quan đến tình trạng phục hình của người cao tuổi, từ đó đưa ra những khuyến cáo phù hợp giúp cho tình trạng phục hình răng mất được cải thiện và nâng cao. Vì vậy chúng tôi nghiên cứu với mục tiêu: Nhận xét đặc điểm một số yếu tố liên quan đến vấn đề phục hình răng đã mất của người cao tuổi ở quận Cầu Giấy, Hà Nội.

\section{2. Đối tượng và phương pháp nghiên cứu}

2.1. Địa điểm nghiên cưu: Một số phuờng quận Cầu Giấy - Hà Nọi

2.2. Thời gian: Tháng 01/2015 đến tháng $125 / 2015$

2.3. Đối tượng nghiên cứu: Người cao tuổi (người tù đủ 60 tuổi trở lên) 
Tiêu chuẩn lựa chọn: Người dân sinh sống tại địa bàn quận Cầu Giấy-Hà Nội từ trên 1 năm, Mất răng và đã có phục hình răng mất.

2.4. Phương pháp nghiên cưu: Mô tả cắt ngang [2]

\section{Kết quả nghiên cứu}

\subsection{Tình trạng phục hình răng mất ở nguời cao tuổi (Biểu đồ 1)}

Những người lao động chân tay có tỷ lệ phục hình răng mất không cao bằng nhóm lao động trí óc và nhóm người làm nghề buôn bán.

\section{Nơi làm phục hình (Biểu đồ 2)}

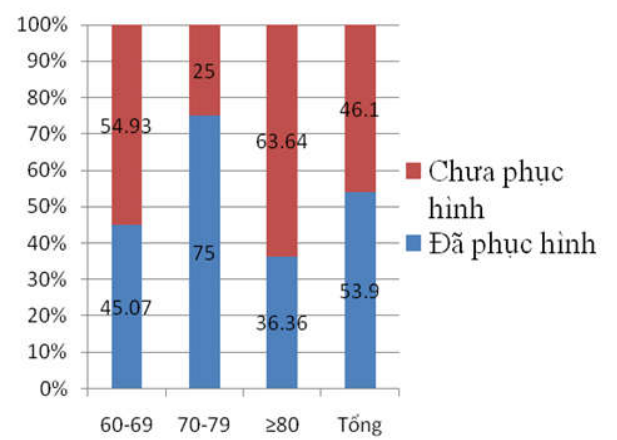

Biểu đồ 1 . Tỷ lệ bệnh nhân đã có phục hình.

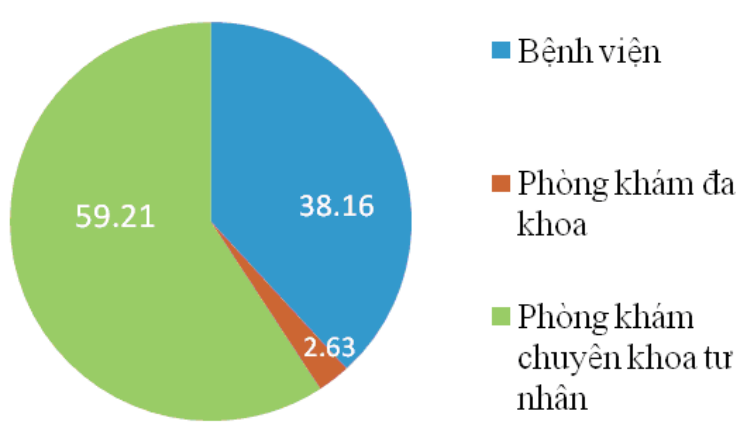

Biểu đồ 2 . Tỷ lệ nơi làm phục hình.

Tỷ lệ bệnh nhân chọn phòng khám chuyên khoa tư nhân là nhiều nhất tiếp theo là bệnh viện, thấp nhất là tại phòng khám đa khoa.

Trong số những người mất răng, chỉ có 53,9\% người đã có phục hình.

\subsection{Một số yếu tố liên quan đến phục hình răng mất ở người cao tuổi.}

Bảng 1. Sự liên quan giữa tỷ lệ mất răng, tỷ lệ phục hình với trình độ văn hóa

\begin{tabular}{lcccccc}
\hline \multirow{2}{*}{ Trình độ văn hóa } & \multicolumn{2}{c}{ Đã có phục hình } & \multicolumn{2}{c}{ Chưa có phục hình } & \multicolumn{2}{c}{$\begin{array}{c}\text { Tống số người mất } \\
\text { răng }\end{array}$} \\
\cline { 2 - 7 } & $\mathrm{n}$ & $\%$ & $\mathrm{n}$ & $\%$ & \\
\hline Không biết chữ & 3 & 33,33 & 6 & 66,67 & 9 & 100,00 \\
Học hết tiểu học & 26 & 50,00 & 26 & 50,00 & 52 & 100,00 \\
\hline Học hết trung học & 25 & 49,02 & 26 & 50,98 & 51 & 100,00 \\
Trung cấp trở lên & 22 & 75,86 & 7 & 24,14 & 29 & 100,00 \\
Tổng & 76 & 54,90 & 65 & 46,10 & 141 & 100,00 \\
& \multicolumn{7}{c}{ Test Chi-Square } \\
\hline
\end{tabular}

NCT có học vấn cao thì tỷ lệ răng mất đã được phục hình cũng cao hơn. 
Bảng 2. Liên quan giữa tỷ lệ mất răng, tỷ lệ phục hình với nghề nghiệp

\begin{tabular}{lcccccc}
\hline Nghề nghiệp & \multicolumn{1}{c}{ Đã có phục hình } & \multicolumn{2}{c}{ Chưa có phục hình } & \multicolumn{2}{c}{ Tổng số người mất răng } \\
\cline { 2 - 7 } & $\mathrm{n}$ & $\%$ & $\mathrm{n}$ & $\%$ & $\mathrm{n}$ & $\%$ \\
\hline Nông dân & 18 & 45,00 & 22 & 55,00 & 40 & 100,00 \\
Công nhân & 14 & 43,75 & 18 & 56,25 & 32 & 100,00 \\
Công chức viên chức & 37 & 64,91 & 20 & 35,09 & 57 & 100,00 \\
Buôn bán & 3 & 100,00 & 0 & 0,00 & 3 & 100,00 \\
Nội trợ & 3 & 75,00 & 1 & 25,00 & 4 & 100,00 \\
Tự do & 1 & 20,00 & 4 & 80,00 & 5 & 100,00 \\
Tồng & 76 & 53,90 & 65 & 46,10 & 141 & 100,00 \\
\multicolumn{5}{c}{ Fisher's exact test } \\
\hline
\end{tabular}

Bảng 3. Mối liên quan giữa nơi làm và chất lượng của phục hình

\begin{tabular}{lcccccc}
\hline \multirow{2}{*}{ Nơi làm phục hình } & \multicolumn{3}{c}{ Tốt } & \multicolumn{2}{c}{ Không tốt } & \multicolumn{2}{c}{ Tống } \\
\cline { 2 - 7 } & $\mathrm{n}$ & $\%$ & $\mathrm{n}$ & $\%$ & $\mathrm{n}$ & $\%$ \\
\hline Bệnh viện & 23 & 79,31 & 6 & 20,27 & 29 & 100,00 \\
Phòng khám đa khoa & 2 & 100,00 & 0 & 0,00 & 2 & 100,00 \\
Phòng khám chuyên khoa tư nhân & 28 & 62,22 & 17 & 37,78 & 45 & 100,00 \\
Tổng & 53 & 69,74 & 23 & 30,26 & 76 & 100,00 \\
& \multicolumn{3}{c}{ Test Chi-Square } \\
\hline
\end{tabular}

Bảng 4. Liên quan giữa thời gian làm phục hình và cảm nhận của người cao tuổi về khả năng ăn nhai

\begin{tabular}{lcccccccc}
\hline \multirow{2}{*}{ Thời gian } & \multicolumn{2}{c}{ Nhai tốt } & \multicolumn{2}{c}{ Khó nhai } & \multicolumn{2}{c}{ Không nhai được } & \multicolumn{2}{c}{ Tổng } \\
\cline { 2 - 9 } & $\mathrm{n}$ & $\%$ & $\mathrm{n}$ & $\%$ & $\mathrm{n}$ & $\%$ & $\mathrm{n}$ & $\%$ \\
\hline Dưới 1 năm & $\mathbf{5}$ & $\mathbf{8 3 , 3 3}$ & 1 & 16,67 & 0 & 0,00 & 6 & 100 \\
Từ 1-4 năm & $\mathbf{2 2}$ & $\mathbf{5 0 , 0 0}$ & 15 & 34,09 & 7 & 15,91 & 44 & 100 \\
Từ 5-9 năm & 10 & 50,00 & 7 & 35,00 & 3 & 15,00 & 20 & 100 \\
Trên 10 năm & 2 & 33,33 & 2 & 33,33 & 2 & 33,33 & 6 & 100 \\
Tổng & 39 & 51,31 & 25 & 32,9 & 12 & 15,79 & 76 & 100 \\
\hline
\end{tabular}

Thời gian sử dụng các răng được làm phục hình càng lâu thì chất lượng phục hình càng giảm.

Các răng được làm phục hình ở bệnh viện được bệnh nhân đánh giá tốt hơn phục hình làm ở phòng khám tư nhân.

\section{Bàn luận}

\subsection{Tình trạng phục hình răng mất ở người cao tuổi}

Trong số những người mất răng, chỉ có 53,9\% người đã có phục hình. So sánh kết quả từ nghiên cứu của Chu Đức Toàn năm 2012 có $50,5 \%$ bệnh nhân mất răng đã có phục hình và nghiên cứu của Trương Mạnh Dũng, Nguyên Văn Bài, Phan Văn Việt với nghiên cứu này thì thấy kết quả tương đương nhau [3-6].

\subsection{Một số yếu tố liên quan đến phục hình răng mất ở người cao tuổi}

Sự liên quan giữa tỷ lệ mất răng, tỷ lệ phục hình với trình độ văn hóa

Có thể thấy học vấn cao thì tỷ lệ răng mất đã được phục hình cũng cao hơn. Những người thuộc nhóm không biết chữ thì tỷ lệ phục hình các răng mất chỉ chiếm $33,33 \%$. Trong khi ở 
những người thuộc nhóm có trình độ từ trung cấp trở lên có tỷ lệ phục hình cho các răng đã mất là $75,86 \%$. Điều này chứng tỏ học vấn có ảnh hưởng tới vấn đề phục hình của bệnh nhân.

\subsection{Liên quan giũa tỷ lệ mất răng, tỷ lệ phuc hình với nghề nghiẹp}

Những người lao động chân tay như nông dân, công nhân, tự do (đa số không có nghề nghiệp ổn định,

Nhóm người làm nghề buôn bán có tỷ lệ răng mất đã làm phục hình cao nhất trong các nhóm nghề nghiệp (100\% người mất răng đã có phục hình). Lý giải cho điều này đó là những người làm nghề buôn bán được khám trong đề tài tuy đã được xem là người cao tuổi nhưng vẫn còn lao động và có thu nhập, kinh tế chưa phải phụ thuộc quá nhiều vào con, cháu. Đồng thời, công việc buôn bán cũng đòi hỏi giao tiếp nên họ cũng chú ý hơn về vấn đề phục hình cho răng mất.

\subsection{Nơi làm phục hình}

Tỷ lệ bệnh nhân chọn phòng khám chuyên khoa tư nhân là nhiều nhất $(59,21 \%)$, tiếp theo là bệnh viện $(38,16 \%)$, thấp nhất là tại phòng khám đa khoa. Điều này có thể do số lượng các phòng khám tư nhân nhiều và phủ rộng khắp, tiện cho việc đi lại của bệnh nhân hơn so với đển bệnh viện, trong khi bảo hiểm y tế lại không chỉ trả cho phục hình răng mất.

\subsection{Mối liên quan giũ̃a nơ làm và chất lượng của phuc hìn}

Các răng được làm phục hình ở bệnh viện được bệnh nhân đánh giá tốt hơn phục hình làm ở phòng khám tư nhân, nhưng bệnh nhân vẫn chọn đến phòng khám tư nhân nhiều hơn do sự tiện lợi về khoảng cách, thời gian có thể làm ngoài giờ, thủ tục ít phiền hà hơn bệnh viện.

\subsection{Liên quan giũ̃a thời gian làm phục hình và cảm nhận của người cao tuổi về khả năng ăn nhai}

Thời gian sử dụng các răng được làm phục hình càng lâu thì chất lượng phục hình càng giảm. Phục hình cho dù có đạt yêu cầu thì sau một thời gian sử dụng sẽ bị suy giảm về chất lượng. Ở các loại hàm tháo lắp, sau một thời gian sử dụng thì hàm đeo không còn sát khít do hiện tượng tiêu sống hàm, hoặc cũng có thể do bệnh nhân mất thêm răng nhưng lại không đến nha sĩ để thêm răng vào hàm... những điều này làm cho khả năng ăn nhai khi mang hàm bị giảm sút đi đáng kể. Còn đối với những phục hình cố định, sau nhiều năm sử dụng sẽ không còn đảm bảo được chất lượng của răng giả nhất là khi bệnh nhân cắn cứng có thể bị vỡ hay do răng trụ không còn chắc; hoặc xuất hiện khe ở gầm cầu sau vài năm sử dụng. Điều này chứng tỏ là thời gian đã sử dụng ảnh hưởng nhiều đến chất lượng của phục hình.

Về cảm nhận của bệnh nhân về thẩm mỹ của phục hình theo thời gian đã sử dụng, với những phục hình vừa mới làm tất cả đều thấy hài lòng. Tuy nhiên, sau một thời gian sử dụng, mức độ hài lòng cũng giảm dần, bệnh nhân lúc này cũng chỉ tạm chấp nhận về mặt thẩm mỹ của phục hình Điều này có thể đến từ việc răng giả sau một thời gian sử dụng bị đổi màu, nhất là những răng giả bằng nhựa của hàm tháo lắp hoặc các loại phục hình cố định bằng kim loại phủ nhựa.

Bệnh nhân mới làm phục hình thì khả năng ăn nhai vẫn đáp ứng tốt. Tuy nhiên theo thời gian, khả năng ăn nhai của các răng được phục hình cũng giảm dần.

\section{Kết luận}

5.1. Một số yếu tố liên quan đến phục hình răng mát của người cao tuổi

- Trình độ học vấn càng cao thì tỷ lệ có phục hình răng mất càng cao.

- Những nghề lao động chân tay có thu nhập thấp tỷ lệ phục hình các răng đã mất thấp hơn những nghề lao động trí óc. Những nghề yêu cầu giao tiếp nhiều có tỷ lệ phục hình răng mất cao.

- Nơi làm phục hình: bệnh nhân lựa chọn phòng khám chuyên khoa tư nhân nhiều nhất, tiếp theo là bệnh viện, thấp nhất là phòng khám đa khoa.

- Thời gian sử dụng phục hình: thời gian sử dụng càng lâu thì chất lượng phục hình, cảm 
nhận của bệnh nhân về thẩm mỹ và khả năng ăn nhai đều giảm.

\section{Tài liệu tham khảo}

[1] Hoàng Tử Hùng, "Tích tuổi và tình trạng răng miệng", Thông tin Y Dược học, Sở Y tế TP Hồ Chí Minh, tập IX, (2002) 37.

[2] Bộ môn Nha Cộng Đồng Viện đào tạo RHM Đại học Y Hà Nội, "Nghiên cứu thực trạng và nhu cầu điều trị bệnh răng miệng ở người cao tuổi Việt Nam", Đề tài cấp Bộ(2014) 5.

[3] Chu Đức Toàn, "Nghiên cứu thực trạng mất răng và nhu cầu điều trị của người cao tuổi tại quận
Đống Đa - Hà Nội”, Luận văn thạc sỹ y học, Trường Đại học Y Hà Nội, (2012) 52.

[4] Trương Mạnh Dũng, "Tình trạng mất răng ở người cao tuối phường Nghĩa Tân, quận Cầu Giấy, thành phố Hà Nội", Tạp chí y học thực hành. 686(11), (2007) 5 .

[5] Nguyễn Văn Bài, "Góp phần đánh giá tình trạng mất răng và nhu cầu điều trị phục hình ở một số tỉnh phía Bắc", Luận văn chuyên khoa II, Trường Đại học Y Hà Nội, (1994) 16.

[6] Phạm Văn Việt, "Nghiên cứu tình trạng, nhu cầu chăm sóc sức khỏe răng miệng và đánh giá kết quả hai năm thực hiện nội dung chăm sóc răng miệng ban đầu ở người cao tuổi tại Hà Nội”, Luận án tiến sĩ y học, Đại học Y Hà Nội, (2004) 14.

\title{
Certain Related Factors Concerning Elder Prosthesis Rehabilitation in Cau Giay District, Hanoi City
}

\author{
Dao Thi Dung ${ }^{1}$, Tran Ngoc Son ${ }^{2}$ \\ ${ }^{1}$ VNU School of Medicine and Pharmacy, 144 Xuan Thuy, Cau Giay, Hanoi, Vietnam \\ ${ }^{2}$ E Hospital, 89 Tran Cung, Nghia Tan, Cau Giay, Hanoi, Vietnam
}

\begin{abstract}
Elder dental health care get more and more attention, especially tooth loss and prosthesis status. Elder prosthesis rehabilitation is extremely important. It improves directly their quality of life. Our Objective of the study is valuation of certain related factors concerning elder prosthesis rehabilitation in Cau Giay District, Hanoi city. Research methods is cross-sectional study. we realize dental examination for 160 seniors, and select the subjects who have tooth loss and wear dental prosthetics. Our researched Results: as high educational level as high proportion of prosthodontic treatment. Manual workers with low income have less prosthodontic therapy than intellectual workers. Communicated occupation have high percentage of prosthodontics. Dental prosthetic care Location: mostly in private clinics then hospitals. As long time of wearing dental prosthesis as low quality of prosthetics, as low patient's satisfaction about aesthetic as well as chewing capacity.
\end{abstract}

Keyword: Factors related to prosthodontics. 